\title{
PENGARUH MODEL PEMBELAJARAN BERBASIS MASALAH DENGAN MEDIA LEMBAR KERJA TERHADAP HASIL BELAJAR SISWA SMA
}

\author{
Yuyum Fahmidani ${ }^{1}$, Yayuk Andayani ${ }^{1}$, Januar Srikandijana ${ }^{2}$, Agus Abhi Purwoko ${ }^{\text {* }}$ \\ ${ }^{\text {I} P r o g r a m ~ S t u d i ~ P e n d i d i k a n ~ K i m i a ~ F a k u l t a s ~ K e g u r u a n ~ d a n ~ I l m u ~ P e n d i d i k a n ~}$ \\ Universitas Mataram \\ ${ }^{2}$ Laboratorium Fisika Dasar, Universitas Mataram \\ *Keperluan korespondensi email: agus_ap@unram.ac.id
}

Received: 5 April 2019

Accepted: 19 Mei 2019

\section{doi: 10.29303/cep.v2i1.1120}

\begin{abstract}
Abstrak
Penelitian ini bertujuan untuk mendeskripsikan pengaruh model pembelajaran berbasis masalah terhadap hasil belajar kimia siswa kelas X SMA Negeri 1 Kediri pada materi konsep oksidasi reduksi. Penelitian eksperimen semu ini menggunakan desain kelompok kontrol non ekuivalen pretestposttest. Populasi penelitian adalah 115 siswa kelas X yang terbagi dalam lima kelas. Dua kelas dipilih menjadi sampel dengan pertimbangan jumlah pertemuan yang sama, yaitu 5 pertemuan $(5 \mathrm{x} 3$ jam pelajaran). Terpilih kelas A sebagai kelas eksperimen yang diberikan perlakuan berupa penerapan model pembelajaran berbasis masalah dengan bantuan lembar kerja siswa (LKS) berbasis masalah dan kelas X B sebagai kelas kontrol yang diajarkan dengan model pembelajaran langsung. Sebelum penerapan model dilakukan, kedua kelas diberikan pretest dengan soal essay dan diperoleh nilai ratarata kelas eksperimen dan kelas kontrol secara berututan adalah 10,15 dan 13,49. Setelah diberikan perlakuan kedua kelas diberikan posttest dengan soal essay dan didapatkan nilai rata-rata kelas eksperimen dan kelas kontrol secara berurutan yaitu 47,84 dan 47,1. Data hasil belajar siswa (hasil tes) dianalisis dengan uji anacova dengan nilai pretest sebagai kovariat. Secara statistik disimpulkan bahwa penerapan model pembelajaran berbasis masalah dengan media lembar kerja berpengaruh terhadap hasil belajar kimia. Artikel ini menyajikan lebih lanjut penjelasan temuan hasil pengamatan pembelajaran yang mendukung data kuantitatif di atas.
\end{abstract}

Kata Kunci: pembelajaran berbasis masalah, LKS, hasil belajar kimia, dan oksidasi reduksi.

\section{THE EFFECT OF CONCEPTUAL UNDERSTANDING PROCEDURES (CUPS) LEARNING MODEL TOWARD THE CHEMICAL PROBLEM SOLVING ABILITY}

Abstract

This study was aimed to describe the effect of implementation of problem based learning on the chemistry learning achievement of class X SMA Negeri 1 Kediri in the topic of oxidation-reduction reactions. This study was quasi experiment with non equivalent pretest-posttest. The study population consists of 115 students of class $X$ distributed into five classes. Two classes were determined as sample based on the meeting schedule, i.e. 5 class meetings. Class X A was then selected as the experimental class which was given the instruction in the form of problem based learning using media of student worksheet and class X B as the control class which was treated with direct instruction. Both classes were given a pretest at the beginning of the program and the results for experiment class and the control class were 10.15 and 13.49, respectively. A posttest was given at the end of the program and the results for experimental class and control class were 47.84 and 47.1. Ancova analysis of the tests conclude that the implementation of problem based learning using student worksheet positively affect student learning 
Chemistry Education Practice, 2 (1), 2019 - 2

Fahmidani, Andayani, Srikandijana, Purwoko

achievement. This article elaborates more in detail the finding on the classroom observations to support the above quantitative data.

Keywords: Problem based learning model, student worksheet, chemistry learning achievement, oxidation-reduction reaction.

\section{PENDAHULUAN}

Ilmu kimia merupakan salah satu mata pelajaran yang dianggap sulit oleh siswa SMA, sehingga hasil belajar kimia mereka pada umumnya masih rendah. Permasalahan ini juga terjadi di SMAN 1 Kediri. Hasil belajar kimia siswa khususnya siswa kelas $\mathrm{X}$ tergolong rendah dengan nilai rata-rata ujian tengah semester ganjil pada tahun ajaran 2015/2016 sebesar 44,68; nilai yang berada di bawah KKM yaitu 75. Hasil wawancara dengan guru kimia di sekolah tersebut menunjukkan bahwa rendahnya hasil belajar disebabkan oleh kurangnya minat siswa untuk belajar kimia. Selanjutnya,penyebab rendahnya minat siswa adalah karena guru tidak menggunakan strategi pembelajaran yang menuntut keaktifan siswa. Dalam pembelajaran di kelas guru menjadi satu-satunya sumber informasi dan siswa hanya mendengarkan penjelasan guru; akibatnya pembelajaran menjadi tidak efektif yang berdampak pada hasil belajar siswa rendah. Oleh karena itu diperlukan model pembelajaran yang menuntut keaktifan siswa agar siswa lebih terlibat dalam proses pembelajaran. Salah satu model pembelajaran yang dimaksud adalah model pembelajaran berbasis masalah (Problem Based Learning atau PBL) (Laksmiwati, dkk., 2019).

Graff dan Kolmos (2003) yang meneliti tentang karakteristik PBL mengungkapkan bahwa PBL pertama kali dikembangkan oleh Howard Borrow di Mc Master University di Kanada pada tahun 1960. Menurut Borrow, PBL memiliki karakteristik utama yaitu, 1) pembelajaran harus bersifat student center (berpusat pada siswa); 2) adanya kelompok (guru bertugas sebagai fasilitator yang membantu siswa mengorganisasikan masalah). Gijselaer dalam Graff dan Kolmos (2003) menyatakan bahwa PBL berkaitan dengan berbagai teori pendidikan diantaranya adalah kontruktivisme, meta-kognitif dan pembelajaran kontekstual. Selcuk (2010) menyatakan PBL adalah model pembelajaran yang mengembangkan kemampuan berpikir kritis siswa dan kemampuan pemecahan masalah serta mengembangkan pemahaman siswa terhadap konsep-konsep yang perlu untuk mengatasi masalah kehidupannya.

Huang (2005) mengemukakan bahwa $89,4 \%$ siswa lebih puas dan lebih interaktif dalam pembelajaran menggunakan PBL. Magdalena (2014) mengungkapkan PBL memiliki lima sintak, yaitu a. orientasi siswa terhadap masalah; b. mengorganisasi siswa untuk belajar; c. membimbing pengalaman individu/kelompok; $d$. mengembangkan dan menyajikan hasil karya; dan e. menganalisis dan mengevaluasi pemecahan masalah;

Model pembelajaran yang digunakan dalam studi ini memiliki ciri utama adanya suatu masalah yang menjadi fokus dalam proses pembelajaran. Permasalahan yang diberikan memotivasi siswa untuk melakukan pembelajaran yang kemudian memunculkan rasa ingin tahu siswa sehingga siswa aktif bertanya dan/atau dapat mengungkapkan pendapatnya. Pembelajaran berbasis masalah juga memberikan kesempatan pada siswa untuk melakukan percobaan yang berkaitan dengan masalah yang disajikan. Kegiatan ini mendorong siswa untuk terlibat dalam proses pembelajaran, seperti pengamatan proses makro yang terjadi dan menuliskan hasil pengamatan dengan benar. Selanjutnya, siswa juga terlatih untuk bekerja sama dan berdiskusi dengan sesama anggota kelompok untuk memutuskan hasil pengamatan dan kesimpulan dari permasalahan yang diberikan. Dalam kaitan ini siswa dituntut untuk lebih kreatif dan mampu menghubungkan proses makro yang diamati dengan konsep yang mendasarinya sehingga siswa mampu menganalisis dan memecahkan masalah.

Melalui pembelajaran seperti ini, siswa mendapatkan pengalaman belajar yang lebih bermakna karena siswa terlibat secara langsung dalam berbagai tahapan pembelajaran. Siswa lebih bertanggung jawab untuk mengingat pengetahuan yang diperoleh sehingga siswa dapat membangun pemahamannya sendiri terhadap materi yang diajarkan dan meningkatkan hasil belajar siswa. 


\section{METODE PENELITIAN}

Penelitian ini merupakan penelitian eksperimen semu yang dilakukan di SMA Negeri 1 Kediri dengan jumlah populasi siswa kelas $\mathrm{X}$ sebanyak 115 orang yang terdistribusi menjadi 5 kelas. Dua kelas ditetapkan menjadi sampel yakni kelas X B (kelas kontrol; 21 siswa) dan X A (kelas eksperimen; 21 siswa) dengan pertimbangan jadwal pelajaran kimia di kedua kelas memiliki jumlah pertemuan yang sama.

Pemberian perlakuan dimulai pada bulan Maret 2016 dan berakhir pada Mei 2016. Penelitian diawali dengan memberikan pretest dengan soal essay untuk kedua kelas. Kemudian dilakukan kegiatan pembelajaran dengan model PBL pada kelas eksperimen dan model pembelajaran langsung pada kelas kontrol. Kelas eskperimen diberikan beberapa masalah, diantaranya adalah masalah reaksi korosi untuk menjelaskan reaksi redoks dan bilangan oksidasi. Siswa diberikan kesempatan menemukan konsep redoks melalui percobaan yang dibantu dengan LKS berbasis masalah. Sementara siswa kelas kontrol diberikan materi terlebih dahulu sebelum melakukan percobaan. Penerapan model dilakukan sebanyak 5 kali pertemuan selama 3 jam pelajaran ( 3 x 45 menit). Pada pertemuan ke enam dilakukan posttest dengan soal essay yang berbeda dari soal pretest untuk menguji pemahaman siswa.

Untuk uji validitas isi dari pretest dan posttest digunakan rumus Aiken's V. Skor dari hasil tes terlebih dulu dikonversi menjadi data interval dengan bantuan metode Rasch. Setelah diperoleh data interval maka uji hipotesis dilakukan dengan teknik analisis kovarian (anakova) dengan mengunakan data pretest sebagai kovariat.

\section{HASIL DAN PEMBAHASAN}

Rata-rata pretest kelas eksperimen dan kelas kontrol secara berurutan adalah 10,15 dan 13,49 sedangkan rata-rata posttest kelas eksperimen dan kelas kontrol secara berurutan adalah 47,84 dan 47,1. Nilai rata-rata kedua kelas tidak berbeda jauh namun dapat dilihat bahwa kedua kelas masing-masing memiliki nilai yang meningkat.

Pada awalnya skor rata-rata kelas eksperimen berada di bawah skor rata-rata kelas kontrol. Pada kondisi akhir skor rata-rata ke dua kelas mengalami kenaikan, namun kenaikan skor kelas eksperimen lebih tinggi dari pada kenaikan skor kelas kontrol sehingga terjadi persilangan garis skor rata-rata. Setelah dikonversi dengan pemodelan Rasch dan dianalisis menggunakan uji anakova diperoleh Fhitung $(4,53)>$ FTabel $(4,08)$. Hal ini menunjukkan bahwa model pembelajaran berbasis masalah dengan LKS berbasis masalah memberikan pengaruh yang positif dan signifikan hasil belajar kimia siswa.

Langkah-langkah pembelajaran berbasis masalah yang diterapkan pada kelas eksperimen terdiri dari (1) orientasi siswa pada masalah, (2) mengorganisasi siswa untuk belajar, (3) membimbing pengalaman individual/kelompok, (4) mengembangkan dan menyajikan hasil karya, serta (5) menganalisis dan mengevaluasi pemecahan masalah (Magdalena, 2014). Penerapan model pembelajaran berbasis masalah dibantu dengan LKS berisi petunjuk yang jelas agar mampu menuntun siswa untuk mengaitkan peristiwa yang diamati dengan konsep yang relevan. Model LKS seperti ini mampu mendorong siswa lebih aktif, terutama dalam tahap pemecahan masalah (Andayani, dkk., 2019).

Tahap awal pembelajaran di kelas eksperimen dilakukan dengan apersepsi yaitu pengenalan masalah berupa penyajian gambar mengenai permasalahan-permasalahan yang terjadi pada kehidupan sehari-hari yang berkaitan dengan konsep oksidasi reduksi. Noordin (2011) menyatakan bahwa PBL dimulai dengan pemberian masalah yang menjadi fokus dalam pembelajaran, dan dilanjutkan dengan kegiatan siswa untuk merencanakan dan bekerja secara langsung dalam menyelesaikan masalah tersebut. Pengamatan proses pembelajaran menunjukkan banyak siswa bertanya saat masalah diberikan. Selcuk (2010) melaporkan bahwa penerapan PBL dapat meningkatkan ketertarikan siswa dalam pembelajaran fisika.

Siswa kelas ekperimen diberikan kesempatan untuk melakukan praktikum sederhana sesuai dengan permasalahan yang diberikan pada apersepsi. Putri dkk (2015) menyatakan bahwa metode praktikum memberikan kesempatan pada siswa untuk mangalami/melakukan sendiri, mengamati, menganalisis mengenai objek, keadaan dan proses yang dipelajari sehingga siswa lebih terlibat pada proses pembelajaran. Pengamatan menunjukkan siswa sangat tertarik pada kegiatan praktikum yang dilakukan; siswa aktif mengajukan pertanyaan mengenai cara kerja maupun tentang hasil pengamatan mereka. Siswa bekerja sama dalam melakukan pengamatan dan 
menuliskannya dalam tabel yang disediakan. Noordin (2011) menyatakan PBL memberikan kesempatan bagi siswa untuk bekerja sama dan memecahkan masalah yang diberikan dengan lebih baik.

Setelah melakukan praktikum sederhana, siswa diberikan kesempatan berdiskusi bersama anggota kelompok mereka untuk menemukan konsep yang relevan dengan hasil pengamatan mereka. Siswa diberikan kesempatan untuk mengemukakan pendapat dan melakukan penyelidikan dengan mengkaji literatur terkait peristiwa mikroskopis yang terjadi. Adanya lembar kerja siswa (LKS) berbasis masalah sangat membantu siswa dalam pelaksanaan diskusi, karena dalam LKS terdapat langkahlangkah sederhana untuk membantu siswa menemukan konsep yang sebenarnya. Siswa menjadi terbiasa berdiskusi dan berkolaborasi untuk menyelesaikan tugas yang diberikan sesuai dengan tuntunan LKS. Jansson dkk (2015) menyatakan pembelajaran yang berpusat pada siswa membuat siswa lebih banyak berdiskusi dan berkolaborasi dengan kelompoknya. Keadaan ini dapat meningkatkan keaktifan siswa sehingga dapat mencapai target hasil belajar yang diinginkan.

Tahap akhir pembelajaran berbasis masalah adalah menganalisis dan mengevaluasi pemecahan masalah. Proses ini memberikan kesempatan bagi siswa menganalisis penyebab dari masalah yang diberikan sehingga siswa dapat menyelesaikannya dengan baik. Siswa dituntun untuk membangun pengetahuan mereka melalui berbagai pertanyaan yang relevan. Siswa dapat membangun pengetahuan mereka berdasarkan permasalahan yang diberikan. Fakta ini sejalan dengan Magdalena (2014) yang mengungkapkan bahwa siswa aktif menemukan sendiri pengetahuannya dengan melakukan seragkaian kegiatan ilmiah seperti diskusi, observasi dan praktikum, karena kegiatan tersebut dilakukan berdasarkan rasa ingin tahu siswa.

Pada model PBL siswa dibimbing untuk dapat mengevaluasi pemecahan masalah melalui pemberian tugas individu berupa latihan soal. Hasil pengamatan menunjukkan siswa awalnya tidak dapat mengerjakan soal dengan baik, namun dengan latihan yang terus dilakukan siswa dapat menyelesaikan soal dengan baik. Peningkatan pengetahuan siswa dapat dibuktikan dari pengamatan bahwa awalnya siswa tidak mampu menuliskan langkah yang benar dalam menentukan bilangan oksidasi senyawa namun pada akhirnya siswa mampu menjawab soal dengan lebih tersruktur sesuai dengan langkahlangkah yang benar.

Pembelajaran yang dilakukan pada kelas kontrol mengikuti sintaks pembelajaran langsung yaitu menyampaikan tujuan pembelajaran dan mempersiapkan siswa, mendemonstrasikan pengetahuan dan keterampilan, membimbing pelatihan, mengecek pemahaman dan memberikan umpan balik serta memberikan kesempatan untuk pelatihan lanjut dan penerapan konsep (Sofiyah, 2011). Sama halnya dengan kelas eksperimen, siswa di kelas kontrol juga diberikan apersepsi dengan memberikan contoh oksidasi reduksi seperti reaksi perkaratan secara lisan. Selanjutnya guru menjelaskan sedikit konsep oksidasi reduksi kemudian siswa diberikan kesempatan untuk melakukan eksperimen dan diskusi dalam proses pembelajarannya. Selama proses pembelajaran, siswa di kelas kontrol cukup aktif bertanya terutama pada saat melakukan percobaan dan mengerjakan LKS. Penyusunan LKS yang digunakan pada kelas kontrol tidak menggunakan langkah-langkah pemecahan masalah, sehingga siswa lebih banyak bertanya pada guru. Secara umum, pembelajaran di kelas kontrol berjalan dengan cukup baik. Pemahaman siswa di kelas kontrol juga mengalami peningkatan yang ditunjukkan oleh jawaban posttest siswa kelas kontrol sudah mampu menjawab soal yang diberikan dengan langkah-langkah yang benar pula.

Jawaban siswa di kedua kelas hampir sama pada soal-soal yang memerlukan perhitungan namun jawaban siswa sedikit berbeda ketika diberikan pertanyaan yang membutuhkan analisis. Siswa di kelas ekperimen mampu menjelaskan mengapa perkaratan terjadi pada pagar yang tidak di cat. Artinya bahwa kelas ekperimen mampu menganalisis penyebab masalah. Hal ini menunjukkan bahwa terjadi peningkatan pemahaman pada siswa kelas eksperimen. Siswa di kelas kontrol meskipun mampu menjawab pertanyaan seputar masalah perkaratan yang terjadi pada pagar rumah, namun jawaban yang diberikan belum sampai pada kesimpulan yang diinginkan. Gorghiu (2014) menyatakan bahwa pemberian masalah nyata dalam penerapan PBL dapat menyebabkan siswa lebih kritis dalam menemukan solusi dari suatu permasalahan.

Berdasarkan pemaparan di atas, dapat dikatakan bahwa pembelajaran dengan menggunakan model pembelajaran berbasis masalah dapat meningkatkan rasa ingin tahu 


\section{Chemistry Education Practice, 2 (1), 2019 - 5}

Fahmidani, Andayani, Srikandijana, Purwoko

siswa terhadap materi sehingga siswa aktif bertanya dan berdiskusi dan melatih siswa untuk menggunakan pikiran mereka untuk menganalisis masalah. Selama proses pembelajaran siswa menjadi lebih fokus dan perilaku siswa dalam memahami materi juga menjadi lebih baik. Hal ini dibuktikan dengan meningkatnya hasil belajar siswa pada posttest.

\section{KESIMPULAN}

Pembelajaran dengan menggunakan model pembelajaran berbasis masalah dapat meningkatkan keaktifan siswa dalam bertanya, rasa ingin tahu siswa terhadap materi. Demikian pula selama proses pembelajaran siswa menjadi lebih fokus. Siswa mendapatkan pengalaman belajar yang lebih bermakna sehingga pemahaman siswa lebih baik yang menyebabkan hasil belajar siswa meningkat.

\section{DAFTAR PUSTAKA}

Andayani, Y., Al-Idrus, S. W., \& Purwoko, A. A. (2019). Penerapan Metode Praktikum Berbasis Kehidupan Sehari-hari Terhadap Keterampilan Proses Sains Siswa Kelas XI MIA MAN 1 Mataram. Chemistry Education Practice, 1(2), 20-26.

Graaff, E. and Anette, K. 2003. Characteristics of Problem Based Learning. International Journal. Engng Ed.19 (5). 34 - 47.

Gorghiu, Gabriel, Luminita, M., Sorin,C., Ana, M., Laura, M. 2015. Problem- Based Learning - An Efficient Learning Strategy In The Science Lesson Context. ProcediaSocial and Behavioral Sciences 191. 2015

Huang,H. 2005. Chinese International Students' Perceptions of the Problem Based Learning Experience. Journal of Hospitality, Leusure, Sport and Tourism Education.4(2). 36 - 43.

Jansson, S., H, Soderstrom., Andersson, P. L., dan Nording, M. L. 2015. Implementation of Problem Based Learning in Environmental Chemistry. Journal of Chemical Education. 5 (4). 35-46.
Laksmiwati, D., Hadisaputra, S., \& Siahaan, J. (2019). Pengembangan Modul Praktikum Kimia Berbasis Problem Based Learning Untuk Kelas XI SMA. Chemistry Education Practice, 1(2), 36-41.

Magdalena,O., Mulyani, S., dan Susanti, E. 2014. Pengaruh Model Problem Based Learning dan Inquiri terhadap Prestasi Belajar Siswa Ditinjau dari Kreativitas Verbal pada Materi Hukum Dasar Kimia Kelas X SMAN 1 Boyolali Tahun Pelajaran 2013/2014. Jurnal Pendidikan Kimia. 3 (4).

Noordin, Muhammad,K., Ahmad,N., Dayana, F., Mohd S. 2011. Problem- Based Learning (PBL) and Project-Based Learning (PjBL) in Engineering Education: a Comparison. Proceeding of the IETEC'11 Conference, Kuala Lumpur, Malaysia. 16-19 Januari 2011.

Putri, A. F. A., Utami, B., dan Nugroho, A. 2015. Penerapan Model Pembelajaran Problem Based Learning (PBL) Disertai Eksperimen untuk meningkatkan Interaksi Sosial dan Prestasi Belajar Siswa pada Materi Pokok Kelarutan dan Hasil Kali Kelarutan di SMA Muhammadiyah 1 Karanganyar Tahun Pelajran 2014/2015. Jurnal Pendidikan Kimia. 4 (4). 27-35

Selcuk, G.S. 2010. The Effect of Problem Based Learning on PreServis Teachers' Achievement, Approaches and Attitudes towards Learning Physics. International Journal of Physical Sciences. 5 (6). 711723.

Sugiyono. 2014. Metode penelitian Kuantitatif, Kuantitatif dan $R \& D$. Bandung: Alfabeta.

Sumintono, B dan Widhiarso, W. 2015. Aplikasi Pemodelan Rasch pada Assessment Pendidikan. Cimahi: Trim Komunikata. 